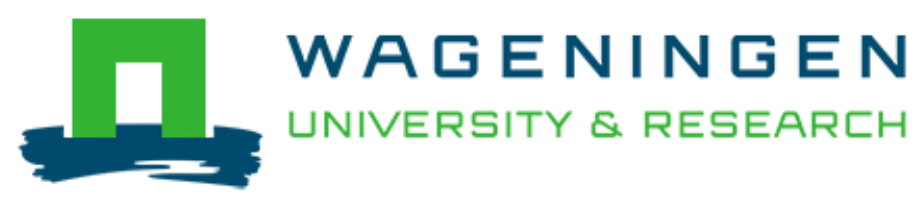

\title{
Teachers' Attitudes Toward Multiculturalism in Relation to General and Diversity-Related Burnout
}

Dubbeld, A., de Hoog, N., den Brok, P., \& de Laat, M.

This is a "Post-Print" accepted manuscript, which has been published in "None"

This version is distributed under a non-commercial no derivatives Creative Commons (c) $(1) \Theta \Theta$ (C) reproduction in any medium, provided the original work is properly cited and not used for commercial purposes. Further, the restriction applies that if you remix, transform, or build upon the material, you may not distribute the modified material.

Please cite this publication as follows:

Dubbeld, A., de Hoog, N., den Brok, P., \& de Laat, M. (2017). Teachers' Attitudes Toward Multiculturalism in Relation to General and Diversity-Related Burnout.. DOI: 10.1080/10564934.2017.1401435

You can download the published version at:

https://doi.org/10.1080/10564934.2017.1401435 
Abstract (European Education) 22-8-16

This study focuses on teachers' burnout and diversity-related burnout in relation to teachers' attitudes toward multiculturalism, as these attitudes are expected to be related to burnout. Results are based on the responses of 120 teachers working at five different urban ethnic diverse junior vocational high schools in the Netherlands. Analyses indicated that, overall, Dutch teachers with assimilative attitudes exhibited a higher level of general and diversityrelated burnout, whereas there was no relationship between having pluralistic attitudes and burnout. In addition, there were no relationships between teacher background variables and attitude and burnout, besides that teachers born in the Netherlands experienced less general burnout, and had less pluralistic attitudes, than teachers born outside the Netherlands.

Keywords: Teachers’ attitudes, Multiculturalism, Burnout, Diversity-related burnout, Teaching, Cultural diversity, Ethnic diversity 
Teachers' attitude toward multiculturalism in relation to general and diversity-related burnout

Every year a large number of teachers feels unable to continue working, due to several reasons, for instance, the pressure of changes in curriculum, the high workload, continuous political involvement, and the increasing diversification of schools and classrooms. Not surprisingly, every year many teachers feel unable to continue working due to burnout or related symptoms (AOB, 2015; Arbo Unie, 2013; Horn et al, 2001). Burnout is a concept used to characterize long-term stress, which is specifically linked to the emotional strain of working frequently and intensively with other people (Maslach \& Schaufeli, 1992). The most widely accepted conceptualization of burnout is found in the work of Maslach and Jackson (1996). They consider burnout as a symptom of emotional exhaustion, depersonalization and reduced personal accomplishment. Emotional exhaustion refers to a depletion of one's emotional resources and the feeling that one has nothing left to give to others psychologically. Such feelings are likely to occur when teachers show strong involvement with the personal needs of students (Schaufeli, Maslach \& Marek, 1993; Abidin \& Robinson, 2002). Depersonalization is described in terms of the development of indifferent and negative attitudes towards students in particular. It is assumed that teachers distance themselves from their students in order to cope with their feelings of emotional exhaustion. The third dimension of burnout involves a negative evaluation of one's personal accomplishments in working with other people (Ginkel, 1987; Van Horn, 2003; Tatar \& Horenczyk, 2003; Verhoeven, \& Maes, 2003). When this is the case, teachers perceive themselves as less effective in their work, particularly with regard to teaching students (Vedder \& Horenczyk, 2006).

Burnout is also a problem in the Dutch context, the focus of the present study: according to the Dutch Central Bureau for Statistics (CBS, 2015) the burnout rate for Dutch teachers is $18 \%$, which is higher than for any other profession. The highest rate of $21 \%$ 
burnout can be found at urban junior vocational high schools (AOB, 2015; Arbo Unie, 2013; CBS, 2015). Teachers appear to be the largest homogeneous occupational group that has been investigated in burnout research in the Netherlands (ArboNed, 2015; CBS, 2013; Schaufeli, Bakker \& Salanova, 2006; Van Daalen, 2010).

Results from a considerable number of investigations into this subject has shown that many teachers experience burnout as a result of, for example, feelings of exhaustion during their career (CBS, 2013; Evertson, \& Weinstein, 2006; Guarino, Santibanez, \& Daley, 2006; Hupkens, 2007; Ingersoll, \& Smith, 2003). One of the factors that is assumed to affect teacher burnout is the growing cultural and ethnic diversity of the students, posing radically different educational, social, and psychological demands on teachers combined with unrealistic expectations (Banks \& McGee Banks, 2004; Vedder, Horenczyk, \& Liebkind, 2006). For example, there is an increasing contradiction in the role of the teacher and the attitudes of society towards teachers is ever changing.

These days diversity in terms of social background, cultural and ethnic origin, language and so on, is a prominent feature of most educational settings in many societies (Banks \& Banks, 2004; Vedder, 2006). The reality of the educational setting at present is one of increasing 'cultural mismatch' between teachers and their students on the one hand, and between teachers and their students’ parents, on the other hand (Vedder \& Horenczyk, 2006). This affects teachers working with immigrant students and makes teachers less able to face the challenges posed by multicultural educational contexts. There is a mismatch between teaching styles developed for- and successfully implemented with - native- born children and those necessary for immigrant students (Hijzen, Boekaerts, \& Vedder, 2006; Rumberger \& Palardy. 2005; Vedder \& Horenczyk, 2006).

The result of this mismatch is mainly immigrant children performing worse on academic tasks and showing behavioral problems in class. All these 'acculturative stressors' 
may negatively affect the personal and professional well-being of teachers who work with immigrant students. An effect of this can be 'diversity-related burnout' (Tatar \& Horenczyk, 2003; Vedder \& Horenczyk, 2006) among teachers. This is a distinct form of burnout, albeit related to the traditional construct. It arises as a result of the extra effort exerted from teachers when working with culturally diverse students. Researchers (Tatar \& Horenczyk, 2003) argue that in urban, multicultural school contexts, teachers have to deal with many stressors, a large number of which are related to the cultural diverse context. Although many teachers have grown up in an ethnically diverse context, teachers are often not well prepared to deal with cultural diversity in the classroom (Banks \& Banks, 2004). Research has shown that teachers lack the knowledge, skills (Wubbels, den Brok, Veldman, \& van Tartwijk, 2006) or are not able to cope successfully with these new educational opportunities (Bowen, 2006; Horn, 2002; Milner, 2006; Tatar \& Horenczyk, 2003; Vink, 2010).

Teachers are human beings who bring their own cultural attitudes, values, hopes and beliefs to the classroom. As indicated by Vollmer (2000), teachers' attitudes and beliefs have a strong impact on the classroom's educational and social climate. So far, no research on teacher burnout and their attitudes at ethnic diverse urban vocational high schools in the Netherlands has been conducted. At the same time, it should be noted that beliefs about inclusivity and heterogeneity in classrooms have been found to be one of the greatest predictors of teaching effectiveness (Stanovitch and Jordan, 1998). It is suggested that the experience of inclusive learning in heterogeneous groups (representative of diversity in ordinary Dutch classrooms) improves interpersonal relations and academic success.

Teachers’ knowledge and beliefs about classroom management strategies in multicultural classrooms were investigated in an exploratory study in the Netherlands (Wubbels, den Brok, Veldman, and van Tartwijk, 2006). In that study, focus-group interviews were conducted with experienced and beginning teachers in Dutch multicultural schools. 
According to the teachers in the focus-groups, teaching in these classrooms requires specific competence in creating positive teacher-student relations, managing and monitoring student behavior, and teaching for student attention and engagement. Further, teachers should be interested in and knowledgeable about students' cultural background and its consequence for student behavior. Teachers' positive attitudes in this respect could facilitate inclusion in a mainstream setting, since positive attitudes are closely and positively related to motivation to work with and to teach ethnic diverse students (Kalyava, 2007). Thus, positive beliefs toward inclusiveness are one of the key factors in facilitating the process of teaching and of student learning.

Little is known about the role of teachers' attitudes toward diversity in relation to burnout. We argue that it is very important to focus on teachers' attitudes in ethnic and cultural diverse settings, in order to understand the way in which they deal with this phenomenon. Therefore, our research focused on teachers' attitudes toward diversity in relation to general and diversity-related burnout. In a previous study (authors, submitted), it was shown that Dutch teachers reported relatively high scores on both burnout scales. In addition, there was a positive relationship between emotional exhaustion, one of the symptoms of burnout, on the one hand and general and diversity-related burnout on the other, but a negative relationship between the burnouts and depersonalization, as well as personal accomplishment, the other two symptoms of burnout. The symptoms explained three times more variance in general burnout than in diversity-related burnout, suggesting that the symptoms may not be that indicative for diversity-related burnout as compared to general burnout. However, the percentages of variance were overall rather low (below 25\%), suggesting that there are other factors that predict or can explain (diversity-related) burnout. One of these factors could be teacher's attitudes toward multiculturalism. 
When studying teachers 'attitudes toward multiculturalism the work of Banks (2006) is of importance. According to Banks, teachers should be aware of the major ideologies related to ethnic pluralism and be able to examine their own philosophical positions. The two major positions he distinguished are the cultural pluralist ideology and the assimilationist ideology. According to Banks, pluralism is a state in which people of all races and ethnicities are considered different, but have equal social standing. In other words, people who differ in appearance or social heritage all share resources roughly equally. Assimilation is the process by which minorities gradually adopt patterns of the dominant culture. In schools with an assimilationist orientation, the task of integrating immigrants is usually seen as marginal, and no major structural or pedagogical changes are considered necessary.

In contrast, schools which adopt a pluralistic orientation assign a central place to education of their immigrants students. The pluralist and assimilationist ideology have an influence on the attitude of teachers in their working context. Educational policy, however, is at all times a cultural policy. School policies and procedures should foster positive multicultural interaction and understanding among students, teachers and support staff (Berry, Sabatier, Sam, Vedder, 2009). In practice teachers’ attitudes have a significant influence on the social atmosphere of the school and attitude of the immigrant students.

\section{The current study}

Much research has been conducted on teachers’ burnout (AOB, 2015; Bakker, Demerouti, \& Euwema, 2005; Travers \& Cooper, 1996; Van Horn, 2003; Verhoeven, \& Maes, 2003), but there is little literature that focuses on teachers’ attitudes toward multiculturalism in relation to burnout or diversity-related burnout, especially among teachers working in urban junior high schools. Only two studies could be identified that addressed some of these concepts (authors, submitted; Tatar \& Horenczyk, 2003). The study by Tatar and Horenczyk (2003) suggested that ethnic and cultural diversity may lead to types of stress 
that add to regular teacher stress, and in extreme cases leads to diversity-related burnout. Their results showed that general and diversity-related burnout are predicted by variables related to teachers' attitudes toward multiculturalism. They found the highest level of diversity-related burnout among teachers categorized as assimilationist and whose work in schools is perceived by themselves to be assimilationist. Those teachers who embraced multiculturalism more strongly reported fewer feelings of stress as a consequence of ethnic diversity in their classrooms (Horenczyk \& Tatar, 2002; Horenczyk \& Vedder, 2006).

The present study builds on the work by Tatar and Horenczyk (2003) and focuses on teachers' attitudes toward multiculturalism and the impact of daily coping with cultural heterogeneous classes in the Dutch context, making it the first study that has addressed these issues in the Netherlands. The situation at these schools has become critical over the last years, with alarming numbers of teachers taking disability leave or retirement as result of stress-related conditions (Arbo Unie, 2013; CBS, 2015). Yet, few studies have actually researched why burnout is so high for these teachers. We wanted to test whether Tatar and Horenczyk‘s (2003) conceptual distinction of teachers’ multicultural attitudes into assimilative and pluralistic and the relationship with both types of burnout was also present in the Netherlands. The study is based on data collected among Dutch teachers at urban junior vocational high schools, who daily face educational challenges posed, by the influx of immigrant students, primarily from Turkey, Morocco, Surinam and the Dutch Antilles, Eastern Europe, and smaller groups from countries in Africa and Asia, into the educational system.

The following research questions will be investigated in the Dutch context: How and to what degree are general burnout and diversity-related burnout associated with teacher's attitudes toward multiculturalism? And is there a relationship between teacher's background 
characteristics and their burnout scores or their attitudes toward multiculturalism? The

following hypotheses were postulated:

1. The more assimilative teachers' attitudes toward a multicultural society, the higher their general and diversity-related burnout.

2. The more pluralistic teachers' attitudes toward a multicultural society, the lower their general and diversity-related burnout.

3. The associations between both attitudes and burnout should be stronger for diversityrelated burnout than general burnout.

\section{Method}

\section{Participants and procedure}

Respondents were asked to complete a self-report questionnaire consisting of two major parts, each including several sections. The questionnaire was handed over to 200 teachers working in five multicultural junior vocational high schools (VMBO), in a highly urbanized western part of the Netherlands. Dutch junior vocational education (VMBO) prepares students for intermediate vocational education, but it does not qualify them for a profession. The intermediate vocational training that follows after the VMBO can prepare students for a wide array of professions; this is called secondary vocational high school (MBO). 120 teachers returned the questionnaire (response rate 60\%). Unfortunately, there was no possibility to find out the reasons of those who did not respond to the questionnaire. In total, 61 female teachers (50.8\%) and male teachers 59 (49.2\%) participated. The average age of the teachers was 43.07 years $(S D=10.14)$, ranging from 22 to 64 years old. The mean number of years of teaching experience was $14.96(S D=10.76)$, ranging from 1 to 40 . The majority of the teachers (98, equivalent to 82\%) was born in the Netherlands, and 22 (18\%) of the teachers were non-native born.

\section{Measurements}


The first section of the questionnaire began with questions about teacher background characteristics; age, gender, education, years of teaching experience, school subject, and country of birth.

In the second section attitudes toward multiculturalism were measured with the 'Multicultural Ideology Scale’, developed by Berry and Kalin (Berry \& Kalin, 1998) and translated to the Dutch general and educational context by translation and back translation (authors, 2007). This scale measures teachers' attitudes toward multiculturalism and consisted of a list of 9 items describing potential characteristics of teachers’ attitudes.

Respondents were asked to indicate their agreement with each statement on a four-point Likert-scale, ranging from 1 (totally disagree) to 4 (totally agree). The instrument consists of two subscales, pluralistic ideology (four items) and assimilationist ideology (five items). We carried out a Principal Component Factor (PCA) analysis on the total set of items. The analysis indicated that two sub dimensions were present, explaining $67 \%$ of the variance. The first factor, pluralistic attitudes, comprised two items (Eigen value $=2.75$, Cronbach's alpha $=$ 0.78). A sample item was "We have to help immigrants from various countries of origin to retain their own cultural background.” The second factor, assimilative attitudes, consisted of four items $($ Eigen value $=1.28$, Cronbach 'alpha $=0.65)$, explaining $54 \%$ of the variance. A sample item is "It is best for the Netherlands when immigrants distance themselves as quickly as possible from their cultural background.” The other three items of the scale had low loadings on either scale, and were therefore, not included in further analyses.

In the third section we used scales on general and diversity-related burnout, developed by Tatar and Horenczyk (2003). The section consisted of a list of 8 items describing potential characteristics of teachers' burnout. The items were adapted from a modified Hebrew version of the Maslach Burnout Inventory (MBI; Maslach \& Jackson, 1986) and were also used in a study by Tatar and Yahav (2000). The modified Hebrew version was 
developed from an extensive study aimed at revealing the relevant items of burnout as reported by Israeli teachers (Tatar and Yahav, 2000; Tatar \& Horenczyk, 2003). We adapted the questionnaire to the Dutch general and educational context by translation and back translation (authors, 2007).

The items were formulated on a 4-point Likert scale with a response format ranging from 1 (I totally disagree) to 4 (I totally agree). A principal component analysis was conducted on these items as well. The first factor, general burnout comprised 5 items (Cronbach's alpha= 0.77). One example of the 5 items for general burnout is: "I feel that working closely with students causes a great deal of tension”. The second factor comprised three items with potential characteristics of teachers' diversity-related (Cronbach's alpha= 0.75). A sample item is: "Daily working with immigrant students frustrates me”.

\section{Statistical analyses}

The Statistical Package for the Social Sciences (SPSS version 19) was used to analyze the data. Firstly, descriptive analyses were carried out. This included mean scores and standard deviations computed for each of the scales of the questionnaire. Next, to answer our research questions, correlations between background characteristics, attitudes and burnout were computed. Lastly, to test the hypotheses, two multiple regression analyses with assimilative and pluralistic attitudes as predictors, country of birth as control variable, and general burnout and diversity-related burnout as dependent variables, respectively, were performed.

\section{Results}

\section{General statistics and research question}

Table 1 provides the means and standard deviations for all variables in this study. The overall means for general and diversity-related burnout were below the mid-point of the scale with mean scores on both scales around 2 (on a scale from 1 to 4). 


\section{[Table 1]}

The scale of pluralistic attitudes had a mean of 2.6, which tells us the score on pluralistic attitudes was a little higher than on the other variables, but still around the midpoint of the scale. As for assimilative attitudes, as well as both types of burnout, the mean was around 2, which is relatively low, e.g. below the midpoint of the scale. The standard deviations were moderate, which means the differences between teachers were not very large.

To explore our research question about the relationship between teachers’ background characteristics and their burnout scores or their attitudes toward multiculturalism, we tested the extent to which demographic characteristics were associated with teachers' burnout and attitudes (see Table 2). Results indicated that there were no significant correlations between the background variables and the main variables, besides for being native born and general burnout and pluralistic attitudes. Respondents who were born in the Netherlands had lower general burnout scores $(M=1.94, S D=.47)$ and lower pluralistic attitudes $(M=2.56, S D=$ .59) than respondents who were not born in the Netherlands $(M=2.17, S D=.51$, and $M=$ 2.84 and $S D=.45$ respectively). This suggests that both types of burnout as well as multicultural attitudes are unaffected by teaching experience, gender, and age. Country of birth did seem to matter, therefore, we controlled for this variable in our regression analyses. In addition, there was a positive relationship between the assimilative attitude of the teachers and both forms of burnout, but there was no statistically significant relationship of teachers pluralistic attitude toward multiculturalism with both forms of burnout.

\section{[Table 2]}

\section{Burnout, diversity-related burnout and multicultural attitudes}

Hypothesis 1 and 2 predicted that (1) the more assimilative teachers' attitude towards a multicultural society, the higher their general and diversity-related burnout, (2) the more pluralistic teachers' attitude towards a multicultural society, the lower their general and 
diversity-related burnout. To see which teachers’ attitude variables predicted burnout and diversity-related burnout, we performed two regression analyses, controlling for country of birth. The results of the first regression analysis showed that country of birth was a significant predictor of general burnout $(\beta=.19, p<.05)$, explaining $4 \%$ of the variance. Attitudes toward multiculturalism explained an additional 10\%. Assimilative attitudes significantly predicted general burnout $(\beta=.34, p<.001)$, whereas pluralistic attitudes did not $(\beta=.09, p=$ 0.32). Thus, general burnout is mainly influenced by assimilative attitudes. Namely, the higher the assimilative attitude, the higher the burnout score.

In the second regression analysis, country of birth was not a significant predictor of diversity-related burnout $(\beta=-.07, p=.48)$, explaining less than $1 \%$ of variance. Attitudes toward multiculturalism explained an additional $12 \%$ of the variance. Assimilative attitudes significantly predicted diversity-related burnout $(\beta=.37, p<.001)$, whereas pluralistic attitudes did not $(\beta=.06, p=0.53)$. Thus, diversity- related burnout is also mainly influenced by an assimilative attitude toward multiculturalism: the more assimilative the teacher's attitudes, the higher the change for diversity-related burnout. This partially supports both hypotheses.

As for Hypothesis 3, the effects of attitudes on burnout should be stronger for diversity-related burnout than general burnout. When comparing both regression analyses we saw that both analyses explained around the same amount of variance, and in fact the analyses for general burnout showed a little more variance explained. Thus, hypothesis 3 was not supported.

\section{Discussion}

The goal of this study was to find out how and to what degree general and diversityrelated burnout are associated with teachers' attitudes toward multiculturalism when working at ethnic diverse urban junior vocational high schools in the Netherlands. The attitudes of 
teachers toward ethnic diversity are regarded crucial for predicting and understanding the extent and degree of both types of burnout.

In our research we predicted that the more assimilative teachers' attitudes toward multiculturalism would be, the higher scores on both types of burnout, and the more pluralistic teachers' attitudes would be the lower the burnout scores. However, while our results confirmed that more assimilative attitudes toward multiculturalism go together with higher general and diversity-related burnout scores, pluralistic attitudes towards multiculturalism appeared unrelated to burnout. Our results showed that assimilative attitudes do not serve as a stress buffer; on the contrary, teachers holding assimilative attitudes exhibited slightly higher levels of both burnouts in our study. In general, working with culturally ethnic diverse students is often considered a stressor and added burden to teachers' already heavy workload (AOB, 2015; ArboNed, 2015; CBS, 2014; Eisikovits, 2008; Horenczyk \& Tatar, 2003).

These results could be explained by the educational tradition that prevails in the Netherlands. According to Eisikovits (2008), many teachers working in ethnic diverse classes are unable to move away from their own assimilationist attitudes and teaching habits, while others do not know how to deal with immigrant students showing some degree of seclusionism. In the absence of systematic training, teachers rely heavily on personal experience as a source of knowledge. Most classroom teachers are socialized within a society, schools, and teacher-education institutions that have mainstream-centric norms and are assimilationist oriented, many teachers are therefore likely to embrace an assimilationist ideology (Banks \& Banks, 2006; Eldering, 2002; Pinto, 2010; Scheffer, 2000; Vedder \& Horenczyk, 2006). Although generally a pluralistic attitude by teachers is likely to be more conductive to the adaptation of their immigrant students, it cannot be ruled out that in some cases immigrant students holding assimilationist orientations will adjust better when their 
teachers and other educational agents also hold assimilationist expectations (Birman, Trickett, \& Vinokurov, 2002; Phinney, Liebkind, \& Vedder, 2001; Vedder \& Horenczyk; 2006). However, it is important to point out that the cultural diversity of the student body is not the problem that needs to be fixed. Instead, schools and teachers should put more effort into teaching in a way that works well for a cultural diverse classroom.

It has been shown that immigrant students in junior vocational high schools in the Netherlands are more likely to drop out and also perform poorer than the native students (CBS, 2013). This is usually attributed to low economic status and poor Dutch language skills (Herweijer, 2009). Even though these factors probably play some role in this, it could also have much to do with the prevalent attitudes of teachers and the way the school dictates how to teach students. Being taught by teachers who feel an immigrant student should give up his or her cultural identity and just embrace the native one, might give students the impression of disrespect for their cultural and ethnic background, and this added stress could contribute to poorer performance.

We further expected that the effects of attitudes of teachers on burnout should be stronger for diversity-related burnout than for general burnout, but when comparing both regression analyses we saw that both analyses explained the same amount of variance. Since diversity-related burnout is more closely related to multiculturalism than general burnout, we had assumed the influence of multicultural attitudes would be stronger for diversity-related burnout as well. However, it appears that it is mainly having assimilative attitudes that increases burnout, regardless of whether these are general burnout complaints or complaints specifically related to teaching ethnic and cultural diverse students. As mentioned earlier, among teachers, it is those teachers who hold assimilationist expectations who showed the highest general and diversity-related burnout, which is similar to the study by Tatar and Tatar (2003) that also failed to find a relationship between pluralistic attitudes and burnout. 
The present study also explored the question whether there was a relationship between teacher's background characteristics and their burnout scores or their attitudes toward multiculturalism. It has been shown in former studies among teachers that burnout can be related to particular demographic variables (e.g., Greenglass, Burke \& Ondrack, 1990; Friedman, 1991; Horenczyk, \& Tatar, 2002; Van Poppel \& Kamphuis, 1992) as well as to work-related factors (e.g., Russell, Altmeier, \& Van Velzen, 1987; Van Ginkel, 1987; Friedman, 1991). However, across countries different results were obtained (Anderson \& Iwanicki, 1984; Friedman, 1991). Our results indicated that there was only a significant correlation between being non-native born and general burnout and pluralistic attitudes. Teachers who were born outside of in the Netherlands had higher general burnout scores and higher pluralistic attitudes than teachers who were born in the Netherlands. A reason could be that those teachers who were not born in the Netherlands were socialized in a more pluralistic society. It might also have to do with the fact that when living in a country where your cultural background is not the same as that of the majority, you might simply be more inclined to see pluralism as a good thing. As for burnout scores, being non native does not affect how much a diverse student population influences your chances for burnout, but it does in general. Perhaps being a non native minority teacher poses extra stress on those teachers, which corresponds with previous research (Horowitz, 1999).

\section{Limitations and implications}

Overall, the findings of this study provide some useful and interesting insights with respect to teachers' attitudes toward multiculturalism in relation to general and diversityrelated burnout. The current study has some limitations that should be mentioned, which might have implications for further research. A first limitation concerned the sample size of the study; the current study was conducted only among teachers working at ethnic diverse vocational high schools in the highly urbanized western part of the Netherlands. The variables 
have only been measured at one time, which can impose restrictions on the generalization of the results. Secondly, the study included self-report measures, meaning that the correlation among the variables may have been inflated by common method variance or the tendency of respondents to provide answers that were socially right. The scale structure and pattern of results require verification on a larger, more representative sample of various ethnic diverse schools.

Several implications can be drawn from the results of the present study. These results are a good start to open up a discussion about the situation of teachers working at junior vocational high schools in the Netherlands. The student population continues to change into a more multicultural one, burnout rates among teachers are very high, yet no strong efforts seem to be made to adapt to this new situation. We think that efforts aiming at reduction and prevention of both burnouts should be of concern for ethic and cultural diverse schools. Several efforts are needed to change the attitudes of teachers and schools, so that the school evolves into an institution that cherishes ethnic and cultural diversity as a resource for development and learning within this context. Multicultural teacher training could play an important role in this (Gay \& Howard, 2000). According to them, multicultural teacher training should focus on three major things: knowledge, attitudes and skills. These three components are generally interrelated and they are likely to affect immigrant students' wellbeing and social adjustment, as well as the personal and professional well-being of teachers who work with them.

Teachers should be provided with sufficient decision space and resources to achieve the intended changes. Moreover, schools should make sure that colleagues and management are backing innovative teachers when they run into problems due to a high workload, opposition or misunderstanding from colleagues, students or their parents. Allow and stimulate schools to develop expertise and acquire resources that facilitate the learning and 
performance of immigrant students. This is especially important if schools are segregated ethnically, culturally or religiously like the urban vocational high schools in the Netherlands. Furthermore, it is important to pay attention to what teachers expect of their students and to create a sufficiently and challenging academic climate that is both emotionally and instructionally supportive to students’ needs.

The insights provided by this study may contribute to the knowledge base that helps affirm ethnic diversity in the classroom, rather than ignore this. To function effectively in ethnically pluralistic environments, it helps if the teachers lessen their assimilative attitudes and move towards pluralistic ideology. Reformed teacher education programs could be designed to help teachers reassess their attitudes. 


\section{References}

Abidin, R. R., \& Robinson, L. L. (2002). Stress, biases or professionalism. Journal of Emotional \& Behavioural Disorders, 10(4), 204-212.

AOB (2015). Algemene Nederlandse Onderwijs Bond. Research about teachers working conditions in relation with burnout. Utrecht.

Arbo Unie (2011). Research about teachers’ burnout in the Netherlands. In Dutch:

Ministerie van Sociale Zaken en Werkgelegenheid (SZW). Den Haag.

Arends-Toth, J., \& Van de Vijver, F.J.R. (2003). Multiculturalism and Acculturation: Views of Dutch and Turkish-Dutch. European Journal of Social Psychology, 33, 249-266.

Authors, (2007). Multiculturalism and stress. In Dutch: Intern rapport, afdeling onderwijsstudies. Leiden University, Leiden.

Authors, (in Press). Diversity-related burnout in secondary vocational urban schools: a verification.

Bakker, A., Schaufeli, W., \& Van Dierendonck, D. (2000). Burnout: prevalentie, risicogroepen en risicofactoren. Burnout: prevail, high-risk group, high-risk factors. In Houtman. J. L. D., Schaufeli, W. B., \& Taris, T. W. (Eds.). Psychische vermoeidheid en werk: cijfers, trends en analyses (pp. 65-82). Psychical tiredness and work: figures, trends and analyses (pp. 65-82). Alphen a/d Rijn: Samson.

Banks, J. A., \& Lynch, J. (1986). Multicultural Education in Western Societies. New York: Praeger Publishers.

Banks, J. A. (2004). Multicultural education: historical development, dimensions, and practice. In J.A. Banks, \& C. McGee Banks (Eds). Handbook of research on multicultural education (pp. 3-29). San Francisco, CA: Jossey-Bass.

Banks, J. A., Cookson, P., Gay., Hawley, W.D., Irvine, J. J., Nieto, S., Schofield, J. W., \& Stephan, W. G. (2001). Diversity within unity: Essential principles for teaching and 
learning in a multicultural society. Seattle, WA: Center for Multicultural Education, University of Washington.

Banks, J. A., \& McGee Banks, C. (2004). Handbook of research on multicultural education. San Francisco, CA: Jossey-Bass.

Banks, J. A. (Ed.) (2004). Diversity and citizenship education: Global perspectives. San Francisco: Jossey- Bass.

Berry, J. W., \& Kalin, R. (1995). Multicultural and ethnic attitudes in Canada: An overview of the 1991 national survey. Canadian Journal of Behavioural Science, 27, 301-320.

Berry, J. W., Phinney, J.S., Sam, D., \& Vedder, P. (Eds.). (2006). Immigrant youth in cultural transition: Acculturation, identity and adaptation across national contexts. Mahwah, NJ: Lawrence Erlbaum Associates.

Birman, D., Trickett, E. J., \& Vinokurov, A. (2002). Acculturation and adaptation of Soviet Jewish refugee adolescents: Predictors of adjustment across life domains. American Journal of Community Psychology, 30 (5), 585-607.

Burke, R. J., Greenglass, E. R., \& Schwarzer, R. (1996). Predicting teacher burnout over time: Effects of work stress, social support, and self-doubts on burnout and its consequences, Anxiety, Stress, and Coping, 9(3), 261-275.

Centraal Bureau voor de Statistiek (2011). Ziekteverzuim Overheid (Absenteïsme Gouvernement). Den Haag: CBS.

Cochran- Smith, M, (1995). Colour blindness and basket making are not the answers: confronting the dilemmas of race, culture, and language diversity in teacher education. American Educational Research Journal, 32(3), 493-522.

Cochran-Smith, M., \& Fries, K. (2005). Researching teacher education in changing times: Paradigms and politics. In M. Cochran-Smith \& K. Zeicher (Eds.), studying teacher 
education: The report of AERA Panel on Research and Teacher Education. Mahwah, NJ: Lawrence Erlbaum.

Cochran-Smith, M., \& Lytle, S. L. (1999). Relationships of knowledge and practice: teacher learning in communities. Review of Research in Education, 24, 249-305.

Coulter, M. A., \& Abney, P. C. (2009). A study of burnout in international and country of origin teachers. International Review of Education, 55, 105-121.

DUO, (2012). Bureau Onderwijsonderzoek: werkdruk in het primair en voortgezet onderwijs. Ministerie van Onderwijs, Cultuur en Wetenschap (OC\&W).

Evertson, C.M., \& Weinstein, C.S. (2006). Classroom management as a field of inquiry. In C.M. Evertson. \& C.S. Weinstein (Eds.). Handbook of classroom management: Research, practice, and contemporary issues (pp. 3-16). Mahway. NJ: Lawrence Erlbaum Associates.

Gay, G., \& Howard, T. C. (2000). Multicultural teacher education for the $21^{\text {st }}$ century. The Teacher Educator, 36(1), 1-16.

Gorski, P. (2006). Complicity with conservatism: the de-politicizing of multicultural and intercultural education. Intercultural Education, 17 (2), 163-177.

Gursel, M., Sunbul, A.M., \& Sari, H. (2002). An analysis of burnout and job satisfaction between Turkish head teachers and teachers. European Journal of Psychology of Education, 17(1), 35-46.

Herweijer, L. (2009). Making up the gap: migrants education in the Netherlands. SCP: The Hague: The Netherlands.

Hijzen, D., Boekaerts, M., \& Vedder, P. (2006). The relationship between quality of cooperative learning, students' goal preferences, and perceptions of contextual factors in the classroom. Scandinavian Journal of Psychology. 47, 9-21.

Ho, R. (1990). Multiculturalism in Australia: A survey of attitudes. Human Relations, 43, 259-272. 
Horenczyk, G., \& Tatar, M. (2002). Teachers' attitudes toward multiculturalism and their perceptions of the school organizational culture. Teaching and Teacher Education, 18(4), 435-445.

Horowitz, T. (1999). Assimilation, monolingualism, unidirectionality, and stereotyping. In T. Horowitz (Ed.), Children of perestroika in Israel (pp. 22-71. Lanham, MD: University Press of America.

Horn, J. E. van., Caljé, D., Schreurs, P., \& Schaufeli, W. B. (1997). Stress en burnout bij docenten: Een literatuuroverzicht. Gedrag \& Organisatie, 10(5), 247-256.

Horn, J. E. van., Schaufeli, W. E., Greenglass E. R., \& Burke, R. J. (1997). A Canadian-Dutch comparison of teacher’s burnout. Psychological Reports, 81(4), 371-382.

Horn, J. E. van, Schaufeli, W. B. , \& Enzmann, D. (2001). Teacher burnout and lack of reciprocity. Journal of Applied Social Psychology, 29(1), 91-108.

Horwitz, E. (1996). 'Even teachers get the blues: recognizing and alleviating language teachers’ feelings of foreign language anxiety’. Foreign Language Annals 29(3), 365-372.

Hupkens, C. (2007). Burnout: the role of psychological workload. (in Dutch). Zoetermeer: Centraal bureau voor de statistiek.

Ingersoll, R. M., \& Smith, T. M. (2003). The wrong solution to the teacher shortage. Educational leadership, 60(8), 30-33.

Johnson, L. (2002). "My eyes have been opened”: White teachers and racial awareness. Journal of Teacher Education, 53(2), 153-167.

Kalyava, E., Gojkovic, D., \& Tsakiris, V. (2007). Serbian teachers’ attitudes toward inclusion. International Journal of Special Education, 2, 30-35. CrossRef.

Leiter, M. P. (1993). Burnout as a developmental process: Consideration of models. In W.B. Schaufeli, C. Maslach, \& T. Marek (Eds.), Professional burnout: Recent developments in theory and research (pp. 237-250). Washington, DC: Taylor \& Francis. 
Leiter, M. P., \& Maslach, C. (2000). Preventing Burnout and Building Engagement: A Complete Program For Organizational Renewal. San Francisco: Jossey-Bass.

Marshall, P. L. (1996). Multicultural teaching concerns: New dimensions in the area of teacher concerns research. Journal of Educational Research, 89, 371- 379.

Maslach, C., Jackson, S. E., \& Leiter, M. (1996). Maslach Burnout Inventory. Manual (3 ${ }^{\text {rd }}$ edn). Palo Alto, CA: Consulting Psychologists Press ( $2^{\text {nd }}$ end,).

Maslach, C., \& Schaufeli, W.B. (1993). Historical and conceptual development of burnout. In W.B. Schaufeli, C. Maslach and T. Marek (Eds) Professional Burnout: Developments in Theory and Research (pp. 1-16). Washington, DC: Taylor \& Francis.

Maes, S., \& Van der Doef, M.(1997). LAKS- DOC, Leidse Arbeids Kwaliteit Schaal voor DOCenten/ Leiden (Quality of work Questionnaire for Teachers). Section of Clinical and Health Psychology, Leiden University, Leiden.

Milner, H. R. (2006). Classroom management in urban schools. In C.M. Evertson \& C.S. Weinstein (Eds). Handbook of classroom management: Research, practice, and contemporary issues (pp. 491-522). Mahwah, NJ: Lawrence Erlbaum Associates.

Niento, S. (2004). Affirming Diversity: The Socio-political Context of Multicultural Education (4th ed.). Boston: Allyn \& Bacon.

Ogbu, J. (1992). Understanding cultural diversity and learning. Educational Researcher, 21 (8), 5-14.

Ogbu, J. (1985). Minority education and caste. The American system in cross- cultural perspective. New York: Academic Press.

Paulle, B. (2005). Anxiety and Intimidation in the Bronx and the Bijlmer: An ethnographic comparison of two schools. Amsterdam: Dutch University Press, 2005.

Phinney, J., Horenczyk, G., Liebkind, K., \& Vedder, P. (2001). Ethnic Identity, Immigration, and Well-being: an international perspective. Journal of Social Issues, 57(3), 493-510. 
Pines, A. M. (1993). Burnout: an extential perspective. In W.B. Schaufeli, C. Maslach and T. Marek (Eds). Professional Burnout: Recent Developments in Theory and Research (pp. 3351). Washington, DC: Taylor \& Francis.

Rumberger, R., \& Palardy, G. (2005). Does Segregation Still Matter? The Impact of Student Composition on Academic Achievement in High Schools. Teacher College Record. 107. 1999-2045.

Schaufeli, W. B., Enzmann, D., \& Girault, N. (1993). Measurement of burnout: A review in W. B. Schaufeli (Ed.). Professional burnout: Recent developments in theory and research (pp. 199-215). Philadelphia, PA, US: Taylor \& Francis.

Stanovitch, P. J., \& Jordan, A. (1998). Canadian teachers’ and principals’ beliefs about inclusive education as predictors of effective teaching in heterogeneous classrooms. Elementary School Journal, 98, 221-238. Cross Ref.

Tatar, M., \& Horenczyk, G. (2003). Diversity- related burnout among teachers. Teaching and Teacher Education, 19, 397- 408.

Tatar, M., \& Yahav, V. (1999). Secondary school pupils’ perception of burnout among teachers. British Journal of Educational Psychology, 69(4), 457-468.

Taylor, S., \& Sobel, D. M. (2001). Addressing the discontinuity of students' and teachers 'diversity: A preliminary study of pre-service teachers' beliefs and perceived skills. Teaching and Teacher Education, 17, 487-503.

Travers, Cheryl, J., \& Cooper, Cary, L. (1996). Teachers Under Pressure, Stress in Teaching Profession. Routledge:, New York, NY

Van Oudenhoven, J. P., Prins, K. S., \& Buuk, B. P. (1998). Attitudes of minority and majority members towards adaptation of immigrants. European Journal of Social Psychology, 28, 995-1013. 
Van Oudenhoven, J. P., Willemsma, G., \& Prins, K.S.(1996). Integration and assimilation of Moroccans, Surnames, and Turks in the Netherlands. De Psycholoog, 31, 468-471.

Vedder, P. (2004). Turkish Immigrant adolescents' adaptation in The Netherlands: The impact of the language context. Estudios de Sociolingüistica, 5(2), 257-276.

Vedder, P. (2006). Black and white schools in the Netherlands. European Education, 38(2), 36- 49.

Vedder, P. \& Horenczyk, G. (2006). Acculturation and the school context. In D.L. Sam \& J.W. Berry (Eds.), Cambridge handbook of acculturation. Cambridge: Cambridge University Press.

Vedder, P., Horenczyk, G., \& Liebkind, K. (2007). Ethno-culturally diverse education settings: problems, challenges and solutions. Educational Research Review, 1, 157-168.

Vedder, P., \& Van de Vijver, F. (2003). De acculturatie en adaptatie van migrantenjongeren in Nederland. Een vergelijkende studie. Migrantenstudies, 19(4), 252-265.

Verhoeven, C. J. M. Maes, S., Kraay, V., Joekes. K.J. (2003). The job demand-control-social support model and wellness/health outcomes: a European study. Psychology \& Health, 18, 421-440.

Verhoeven, C. J. M., Kraay, V., Joekes, K.J. \&, S. (2003). Job conditions and wellness/ health outcomes in Dutch secondary school teachers., Psychology \& Health, 18, 473-487.

Vink, A. (2010). Witte zwanen, zwarte zwanen. De mythe van de zwarte school. In Dutch: segregatie in scholen en samenleving. Amsterdam: Querido.

Wendekind, V. R. (2001). Teachers, the South African state, and the desegregation of schools in the 1990's. In N. Shimahara \& I. Holowinsky \& S. Tomlinson- Clarke (Eds.), Ethnicity, race, and nationality in education: A global perspective (pp. 131- 164). Mahwa, NJ: Lawrence Erlbaum. 
Wubbels, T., Brekelmans, M., Hooymayers, H. P. (1991). Interpersonal teacher behavior in the classroom, in: B. J. Fraser \& H. J. Walberg (Eds). Educational environments (Oxford, Pergamon Press), 141-160.

Wubbels, T., den Brok, P., Veldman, I., \& van Tartwijk, J. (2006). Teacher’s interpersonal competence for Dutch secondary multicultural classrooms. Teachers and Teaching Education, 12, 407-433.

Wubbels, T., \& Levy, J. (1991). A comparison of interpersonal behaviour of Dutch and American teachers. International Journal of Intercultural Relations, 15, 1-18. 
Table 1. Means and standard deviations attitudes and burnouts

Mean

Std Deviation

General Burnout

2.0

0.5

Diversity-related burnout

2.1

0.5

Attitudes pluralistic

2.6

0.6

Attitudes assimilative

1.9

0.5

Note: The items of both burnouts and attitudes were scored on a four point scale. 
Table 2. Correlations between all main variables $(\mathrm{N}=120)^{\mathrm{a}}$

\begin{tabular}{|c|c|c|c|c|c|c|c|c|c|}
\hline & 1 & 2 & 3 & 4 & 5 & 6 & 7 & 8 & 9 \\
\hline 1. & - Age & .02 & -.1 & .10 & -.12 & .03 & .06 & .05 & .05 \\
\hline & Gender & --- & .06 & -.08 & -.12 & .05 & .08 & .15 & .06 \\
\hline & - Education & & --- & -.08 & -.08 & .01 & -.17 & -.22 & -.11 \\
\hline 4. & - Teaching experience & & & --- & -.18 & .08 & .01 & .06 & .10 \\
\hline & Country of birth & & & & --- & -.11 & $.18^{*}$ & $.19 *$ & -.07 \\
\hline & - Attitude assimilative & & & & & --- & $-.33 * *$ & $.29 * *$ & $.35^{* *}$ \\
\hline & - Attitude pluralistic & & & & & & --- & .02 & -.07 \\
\hline & - General burnout & & & & & & & --- & $.52 * *$ \\
\hline & Diversity-related burn & & & & & & & & --- \\
\hline
\end{tabular}

a Pearson correlations for all variables, except education and teaching experience (Spearman for most variables and Phi for correlation with gender).

**. Correlation is significant at the 0.01 level (2- tailed)

*. Correlation is significant at the 0.05 level (2- tailed) 